ReVIEW ARTICLE

\title{
PROMINENCE, PHRASING, AND MOVEMENT
}

\author{
HISAO TOKIZAKI \\ Sapporo University*
}

Prosody, Focus, and Word Order, by Maria Luisa Zubizarreta, MIT Press, Cambridge, MA, 1998, xii+213pp.

Keywords: syntax-phonology interface, intonational phrase, minimalist, thetic/categorical judgment, unaccusative/unergative verbs

\section{Introduction}

The interface of various components has been one of the interesting research topics in generative grammar which assumes a modular system of grammar. Zubizarreta's book is a recent result of the study on the syntax-phonology interface based on the minimalist program proposed by Chomsky (1995) inter alia. I will give an overview of her analysis in section 2 and point out some conceptual and empirical problems with her theory in section 3. I will also propose an alternative analysis and suggest an extension of Zubizarreta's work in section 4 .

\section{An Overview of Zubizarreta (1998)}

2.1. Assertion Structure and the Theoretical Framework

In chapter 1, titled "Introduction," Zubizarreta defines the notions of focus and topic, and outlines the theoretical framework she assumes.

* I am grateful to Elisabeth Selkirk and two anonymous reviewers for their valuable comments and suggestions, which helped me to clarify a number of points. I would like to thank Heiko Narrog for his help with German. Thanks also go to William Green for suggesting stylistic improvements. All errors are, of course, my own. 
Following Chomsky $(1972,1976)$ and Jackendoff (1972), she assumes that focus is defined as the nonpresupposed part of the sentence. She also argues that the focus structure should be represented in the Assertion Structure (AS) of the sentence, a more abstract representation derived from LF via some interpretive mechanisms. For example, the answer to a multiple $w h$-question $(1)$ has $(2 \mathrm{a}, \mathrm{b})$ as its AS:

(1) (Who bought what?)

[F Mary] bought ${ }_{F}$ the newspaper], ${ }_{F}$ Peter $]$ bought $[F$ the book], ...

(2) a. there is an $(x, y)$, such that $x$ bought $y$

b. the $(x, y)$, such that $x$ bought $y=$ (Mary, the newspaper), (Peter, the book), ...

Zubizarreta refers to a syntactic structure annotated with the diacritic $[\mathrm{F}]$ as the F-structure of S. In (1) the diacritic $[\mathrm{F}]$ is used to mark the constituent that is interpreted as focused or as part of the focus (and as equivalent to $[+F]$ ) (See Jackendoff (1972) and Selkirk (1984) for Fmarking). A constituent that is not marked $[\mathrm{F}]$ will be interpreted as the presupposition or as part of the presupposition (and as equivalent to $[-F]$ ). Zubizarreta's main motivation for representing the focus structure of a sentence in terms of its AS rather than at LF is that focus need not constitute a syntactic constituent as shown in (1).

The theoretical framework Zubizarreta assumes is the minimalist program proposed by Chomsky (1995). She argues, however, that the architecture of the grammar should be diagramed as in (3):

(3)

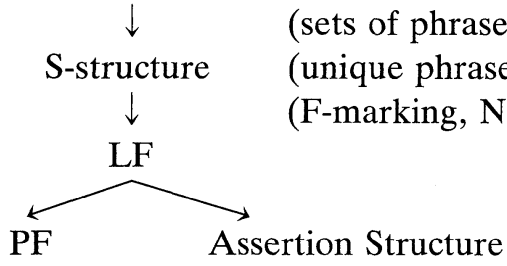

S-structure is the first single phrase marker formed by Merge, the operation combining syntactic objects. F-marking, the Nuclear Stress Rule (NSR), the Focus Prominence Rule (FPR), and prosodically motivated movement (p-movement) apply to this structure to give LF, which is assumed to be the input to PF and AS. The last three of these post-S-structure rules, i.e. NSR, FPR, and p-movement, are the main topics of Zubizarreta (1998), and I will illustrate these rules in turn below. 


\subsection{NSR, FPR, and P-Movement}

One of the main proposals Zubizarreta makes is that the NSR, originally proposed by Chomsky and Halle (1968), should be modularized and formulated in syntactic terms such as selectional ordering and asymmetric c-command. Selectional ordering, based on the lexicosyntactic structures proposed in Hale and Keyser (1993), is established by the ordered sequence of selected heads. Zubizarreta assumes the syntactic structures in (4a-d) for transitives, unergatives, unaccusatives, and ditransitive directional predicates, respectively (pp. 53-55). ${ }^{1}$

(4) a. $\left[\mathrm{D}_{1}\left[\mathrm{~V}_{1}\left[\mathrm{~V}_{2} \mathrm{D}_{2}\right]\right]\right]$

b. $\left[\mathrm{D}_{1}\left[\mathrm{~V}_{1}\left[\left[\mathrm{~V}_{2} \mathrm{D}_{2}\right] t_{2}\right]\right]\right]$

c. [V D]

d. $\left[\mathrm{D}_{1}\left[\mathrm{~V}_{1}\left[\mathrm{D}_{2}\left[\mathrm{~V}_{2}\left[\mathrm{P}_{3} \mathrm{D}_{3}\right]\right]\right]\right]\right]$

$(4 \mathrm{a}, \mathrm{b})$ contain two verbal heads, each of which selects an argument, and $\mathrm{D}_{2}$ is the lowest constituent in a selectional chain. In (4c) D, which is selected by $\mathrm{V}$, is the lowest constituent in the selectional chain. In (4d) $V_{2}$ selects the prepositional predicate $P_{3} . P_{3}$ in turn selects a nominal argument $D_{3}$, which constitutes the lowest constituent in a selectional chain. The definition of the selectional ordering is shown in (5) (p. 52).

( 5 ) $\left(\mathrm{C}, \mathrm{T}, \mathrm{V}_{1}, \ldots, \mathrm{V}_{i}, \mathrm{P} / \mathrm{V}_{m}, \mathrm{D}_{m}\right)$, with possibly $\mathrm{m}=1$

$\left(\mathrm{C}, \mathrm{T}, \ldots, \mathrm{V}_{i}, \mathrm{D}_{i}\right.$ ), for $i=1,2, \ldots, m-1$ (for the cases where $m>1)$

where $\mathrm{D}_{i}, i=1,2, \ldots, m-1$ is the nominal argument of $\mathrm{V}_{i}$ (for the cases where $m>1$ ) and $\mathrm{D}_{m}$ is the nominal argument of the lowest (possibly only) verb or prepositional predicate $\left(\mathrm{P} / \mathrm{V}_{m}\right)$ in the selectional ordering.

The sequence $\mathrm{V}_{1}, \ldots, \mathrm{V}_{i}, \mathrm{P} / \mathrm{V}_{m}, \mathrm{D}_{m}$ is the ordered analysis of the lexical verbs or prepositions. $\mathrm{D}_{m}$ is the nominal argument of the last (possible only) element $\mathrm{P} / \mathrm{V}_{m}$ in the selectional ordering, and $\mathrm{D}_{i}, i=1$, $2, \ldots, m-1$ is the nominal argument of $\mathrm{V}_{i}$ when $\mathrm{V}_{i}$ exists. The partial ordering in (5) can be represented as the tree in (6) (p. 53):

(6) $\mathrm{C}-\mathrm{T}-\mathrm{V}_{1} \longleftarrow \ldots \quad \mathrm{V}_{\mathrm{i}}\left\lceil\ldots \mathrm{P} / \mathrm{V}_{m}-\mathrm{D}_{m}\right.$

$$
\mathrm{D}_{1} \ldots \quad \mathrm{D}_{\mathrm{i}} \ldots
$$

1 The unergative structure is analyzed as a type of covert transitive. The lower $\mathrm{V}$ selects a cognate object, which is incorporated into its selecting head. 
The notion of asymmetric c-command is defined as in (7).

(7) $\alpha$ asymmetrically c-commands $\beta={ }_{\text {def }} \alpha$ c-commands $\beta$ and $\beta$ does not c-command $\alpha$.

Zubizarreta posits the following definition of c-command:

( 8 ) $\alpha$ c-commands $\beta={ }_{\text {def }} \alpha$ and $\beta$ are visible to the syntactic computation (i.e., are either heads or maximal projections (excluding segments)) and (a) $\alpha$ and $\beta$ are sisters or (b) there exists a $\chi$ such that $\alpha$ and $\chi$ are sisters and $\chi$ dominates $\beta$.

Zubizarreta also introduces the convention stated in (9).

(9) If $\alpha$ c-commands $\beta$, then $\alpha$ c-commands $\chi, \chi$ a projection of $\beta$ that does not contain $\alpha$.

Whereas (8) defines a direct relation of c-command between two nodes, (9) defines an indirect relation of c-command between two nodes. Consider the structure in (10).

(10) $\left[\mathrm{xP} Z \mathrm{P}\left[\mathrm{x}^{\prime} \mathrm{X}\right.\right.$ YP $\left.]\right]$

$\mathrm{ZP}$ c-commands $\mathrm{X}$ and hence indirectly the projection $\mathrm{X}^{\prime}$ of $\mathrm{X} . \quad \mathrm{ZP}$ is not c-commanded by $\mathrm{X}^{\prime}$ because $\mathrm{X}^{\prime}$ is not visible for the computation. Thus $\mathrm{ZP}$ asymmetrically c-commands $\mathrm{X}^{\prime}$. In the adjunction structure (11), YP asymmetrically c-commands $\mathrm{XP}_{1}$.

(11) [XP2 YP XP 1$]$

$\mathrm{YP}$ c-commands the head of $\mathrm{XP}_{1}$, but $\mathrm{XP}_{1}$ itself is a segment and invisible for the computation. Then $\mathrm{YP}$ c-commands $\mathrm{XP}_{1}$ indirectly by (9) and asymmetrically c-commands $\mathrm{XP}_{1}$.

With these definitions, Zubizarreta proposes to revise the NSR as in (12) (pp. 19, 124): ${ }^{2}$

(12) Revised NSR

a. S-NSR: Given two sister nodes $\mathrm{C}_{\mathrm{i}}$ and $\mathrm{C}_{\mathrm{j}}$, if $\mathrm{C}_{\mathrm{i}}$ and $\mathrm{C}_{\mathrm{j}}$ are selectionally ordered, in the sense of $[(5)](=[(6)])$, the one lower in the selectional ordering is more prominent, or

b. C-NSR: Given two sister nodes $\mathrm{C}_{\mathrm{i}}$ and $\mathrm{C}_{\mathrm{j}}$, the one lower in the asymmetric c-command ordering is more prominent.

2 Zubizarreta (p. 56) also shows the NSR for German which has 'otherwise' instead of 'or' at the end of (a). Here I show the NSR for English where the S-NSR and the C-NSR are unordered. 
The following examples in (13a) and (13b) illustrate the S-NSR (selection-driven NSR) and the C-NSR (constituent-driven NSR), respectively:

(13) a. A bóy has danced.

b. John ate the pie in the kítchen.

In (13a), the verb dance selects its argument a boy. Then a boy, the lowest argument in the selectional ordering, receives Nuclear Stress (NS) by the S-NSR. ${ }^{3}$ In (13b) kitchen, the lowest constituent in the asymmetric c-command ordering, receives NS by the C-NSR. Zubizarreta suggests that the S-NSR and the C-NSR are unordered in English, unlike in German where the S-NSR has primacy over the C-NSR (p. 71). For example, (13a) may also be pronounced with NS on the verb in an out-of-the-blue context:

(14) A boy has dánced.

Here the DP a boy, which is lower than the verb danced in the selectional ordering, does not receive NS by S-NSR. The C-NSR instead assigns NS to the verb, the lowest constituent in the asymmetric c-command ordering.

Note also that the revised NSR applies to metrical sisters, and not to syntactic sisters. Zubizarreta first introduces the relevant notion of metrical nondistinctness in (15). ${ }^{4}$

(15) Constituents $\mathrm{X}$ and $\mathrm{Y}$ are metrically nondistinct $={ }_{\operatorname{def}} \mathrm{A}$ and $\mathrm{B}$ dominate the same set of metrically visible heads.

The notion of metrical sisterhood is formalized as in (16).

(16) Constituents $X$ and $Y$ are metrical sisters $=_{\text {def }}$ there exist two constituents $\mathrm{Z}$ and $\mathrm{W}$ such that (a) $\mathrm{Z}$ and $\mathrm{W}$ are sisters and (b) Z (resp. W) is metrically nondistinct from $\mathrm{X}$ (resp. Y).

3 Zubizarreta uses the term Nuclear Stress for prominent syllables. However there are other terms to represent phonological prominence, such as sentence stress (Gussenhoven (1983)) or pitch accent (Selkirk (1995)). Although caution is needed, I will gloss over the differences between these terms and use NS interchangeably to make the argument straightforward.

4 Zubizarreta assumes that the following elements are metrically invisible:

(i) a. defocalized and anaphoric constituents in English, in German, and in French (p. 74)

b. function words (p. 47)

c. empty categories (p. 49)

For illustration of (ia), see (19) and (20). For illustration of (ib), see (38) and footnote 15. 
Zubizarreta adopts the following convention for the application of the NSR (p. 43):

(17) Convention for the application of the NSR

Given two analyses of the syntactic tree $\ldots, C_{i}, \ldots C_{j}, \ldots$ and $\ldots, \mathrm{K}_{\mathrm{i}}, \ldots \mathrm{K}_{\mathrm{j}}, \ldots$ such that $\ldots, \mathrm{C}_{\mathrm{i}}, \ldots \mathrm{C}_{\mathrm{j}}, \ldots$ and $\ldots, \mathrm{K}_{\mathrm{i}}, \ldots$ $\mathrm{K}_{\mathrm{j}}, \ldots$ are metrically nondistinct at $\left(\mathrm{C}_{\mathrm{i}}, \mathrm{K}_{\mathrm{i}}\right)$ and at $\left(\mathrm{C}_{\mathrm{j}}, \mathrm{K}_{\mathrm{j}}\right)$ and $\left(\mathrm{C}_{\mathrm{i}}, \mathrm{C}_{\mathrm{j}}\right)$ meets some condition $\mathrm{P}$ of the structural description of the NSR in the standard sense, then $\left(K_{i}, K_{j}\right)$ is taken to meet $\mathrm{P}$ as well.

This convention ensures that relative prominence between two constituents is established by the NSR if and only if they are both metrically visible (p. 43).

The F-structure of the sentence is constrained by the location of main prominence. Zubizarreta formalizes this as the following rule (p. 21):

(18) Focus Prominence Rule (FPR)

Given two sister categories $\mathrm{C}_{\mathrm{i}}$ (marked $[+\mathrm{F}]$ ) and $\mathrm{C}_{\mathrm{j}}$ (marked $[-\mathrm{F}]$ ), $\mathrm{C}_{\mathrm{i}}$ is more prominent than $\mathrm{C}_{\mathrm{j}}$.

Zubizarreta also argues that the domain of the NSR is restricted in English (and German) to focused and nonanaphoric constituents (p. 47):

(19) A: (I would like to know) who has written a book about ráts.

B: [F The cat in the blue hát] has written a book about râts.

(20) Mary walked in. John kíssed her.

She argues that the elements written in italics are defocalized and anaphoric, and are metrically invisible for the NSR in English and German. ${ }^{5}$ In other words, Germanic languages resolve the contradiction between the output of the NSR and the output of the FPR by treating defocalized and nonanaphoric constituents as metrically invisible for the NSR.

In Romance languages, however, only the C-NSR applies, and all phonologically overt constituents are metrically visible. Thus Spanish

5 Zubizarreta suggests that the stress within the defocalized phrase in (19B) has been copied from the context question (19A) directly. She refers to it as the echo stress and postulates that:

(i ) A word that bears an echo stress within a phrase is rhythmically subordinate to the word that bears a nonecho stress within the same phrase. 
(21a) and Italian (22b) are not appropriate answers to the specified context question, unlike Germanic languages (cf. (19B)). As a Last Resort, p-movement of the defocalized phrase leaves the focused phrase in a position to receive NS via C-NSR, as shown in (21b) and (22b) (NS in Romance is marked with underlining to avoid confusion between accent marks in these languages and the conventional orthographic mark for word stress) (pp. 20, 22): ${ }^{6}$

(21) (Who ate an apple?)
a. *Juan comió una manzana. Juan ate an apple
b. Comió una manzana Juan.

(22) (Who ate an apple?)

a. *Gianni ha mangiato una mela. Gianni has eaten an apple

b. ?Ha mangiato una mela Gianni.

Note that $(22 b)$ is not a perfect sentence. Zubizarreta argues that in Italian (22b), the movement of the verb and the object violates the Relative Weight Constraint (RWC) (p. 23):

(23) The Relative Weight Constraint

$\mathrm{P}$-movement of constituent A across constituent B is degraded if A is "metrically heavier" than B.

$A$ is metrically heavier than B if A is branching and B is not (where only metrically visible material counts for computing "branchingness"), unless B has heavier pitch than A.

In (22) ha mangiato una mela is metrically heavier than Gianni because the former is branching and the latter is not. Zubizarreta also argues that Spanish VOS order in (21b) is derived from VSO via leftward movement of $\mathrm{O}$ across $\mathrm{S}$. She assumes that this movement does not violate the RWC and gives the acceptable sentence (21b).

${ }^{6} \mathrm{P}$-movement is formulated as shown in (i) (p. 140):

(i) Affect the nodes $\alpha$ and $\beta$ iff these nodes have contradictory prosodic properties.

Zubizarreta defines a prosodically contradictory structure as follows (p. 139):

(ii) $\ldots\left[{ }_{\delta}\left[\alpha \mathrm{ph}^{*}\right] \ldots\left[\beta \mathrm{ph}^{*}\right]\right]$, where $\alpha$ and $\beta$ are metrical sisters.

In (ii), $p h$ stands for phonological content and [ $\left.\mathrm{ph}^{*}\right]$ for prosodic strength. A node $\alpha$ is assigned main prominence by FPR and $\beta$ is assigned main prominence by NSR. 


\section{Problems and Discussion}

\subsection{The Modularized NSR}

Zubizarreta's argument is straightforward and her analysis explains a wide range of data in Germanic and Romance languages. There are still some conceptual and empirical problems in her analysis, however.

First, the idea of a modular NSR is not straightforward. The original NSR proposed by Chomsky and Halle (1968) depends on the linear order of words. Zubizarreta replaces the original NSR with the CNSR in terms of asymmetric c-command. ${ }^{7}$ This replacement has become possible due to the recent study of phrase structure, which claims that the linear order of words corresponds to the hierarchical structure of constituents (cf. Larson (1988), Kayne (1994)). On the other hand, the S-NSR has a totally different origin and character from the C-NSR because it is defined in terms of selectional ordering. It incorporates the basic insight of Schmerling (1976): predicates receive lower stress than their arguments. It also subsumes Selkirk's (1984) and Gussenhoven's $(1983,1992)$ view that the predicate-argument structure is relevant in determining NS. Thus S-NSR is an independent factor in determining the position of NS and should not be included as a part of the NSR. This is also clear from Zubizarreta's argument that the SNSR is not active in Romance languages. ${ }^{8}$

Second, Zubizarreta only mentions the NSR and does not consider the CSR (Compound Stress Rule), the other rule Chomsky and Halle

7 In this sense, Zubizarreta develops Cinque's (1993) idea that the right-most constituent in a phrase is the lowest in the syntactic tree and is most prominent.

8 Alternatively, we could formulate constraints (instead of the NS assignment rules, i.e. the S-NSR and the C-NSR) such that the lowest constituent in selectional ordering and in asymmetric c-command ordering are forbidden to occur without NS. Then we could argue that NS is determined by the interaction of these two constraints in the framework of optimality theory. In German, the constraint banning the selectionally lowest constituent without NS outranks the constraint banning the lowest constituent in asymmetric c-command without NS. In English these constraints are equal in ranking. In Romance languages, the constraint banning the lowest constituent in asymmetric c-command without NS outranks the constraint banning the selectionally lowest constituent without NS. The effect of the S-NSR does not appear in Romance languages because the C-NSR, unlike the S-NSR in German, can always apply to any structure. This is a promising approach to the analysis of language variation. 
(1968) proposed. Cinque (1993) proposes a generalization about the NSR to the effect that NS falls on the most embedded element. He also tries to extend this analysis to the CSR, which seems to be successful. For example, Cinque assumes that kitchen towel rack ('rack for kitchen towel') and kitchen tówel rack ('towel rack in the kitchen') have the following structures, respectively (Cinque (1993: 276)):

(24) a. [[[[kítchen] towel]] rack]

b. [[kitchen] [[tówel] rack]]

The compound stress falls on the most embedded element, namely kitchen in (24a) and towel in (24b). However it is not clear how Zubizarreta can extend her analysis to compounds. Let us assume Kayne's (1994: 40) analysis of compounds, which claims that compounds are derived from head to head adjunction. In (24a) kitchen adjoins to towel and kitchen towel in turn adjoins to rack as in (25):

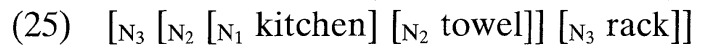
According to (8), no c-command relation holds between kitchen, towel, and rack because segments of $\mathrm{N}_{2}$ and $\mathrm{N}_{3}$ are invisible for the computation. Thus the C-NSR cannot apply to (25)..$^{9}$ Nor can the S-NSR, because there is no selectional ordering between kitchen, towel, and rack. In fact, Zubizarreta admits that adjunction to a head is problematic, and claims that its stress pattern is governed by morphophonological rules (p. 36). Thus Zubizarreta's analysis of phrasal stress is difficult to extend to compound stress. If it cannot explain compound stress, it may be claimed that her analysis misses an important generalization which Cinque (1993) tries to capture.

\subsection{PF Restructuring and the Relative Weight Constraint}

Zubizarreta also assumes a PF restructuring of the metrically interpreted syntactic tree for sentences such as the following (pp. 90,148)

9 Suppose that we assume Kayne's (1994: 16) definition of c-command instead of Zubizarreta's (8).

(i ) $\mathrm{X}$ c-commands $\mathrm{Y}$ iff $\mathrm{X}$ and $\mathrm{Y}$ are categories and $\mathrm{X}$ excludes $\mathrm{Y}$ and every category that dominates $\mathrm{X}$ dominates $\mathrm{Y}$.

( $\mathrm{X}$ excludes $\mathrm{Y}$ if no segment of $\mathrm{X}$ dominates $\mathrm{Y}$.)

Then kitchen and towel both asymmetrically c-command rack in (25) (cf. Kayne (1994: 20)). Then Zubizarreta's C-NSR applies to (25), assigning prominence to rack. This is a wrong result, however. 
(cf. Chomsky and Halle (1968: 372)):

(26) a. (This is the cát) (that chased the rát) ...

b. (Max pút) (all the boxes of home fúrnishings) (in his cár).

She suggests that the syntactic tree is broken up into smaller trees that correspond to the intonational phrases in (26a). She also argues that (26b) is achieved by restructuring the tree and inserting an intonational boundary before and after the heavy constituents. However, she does not formulate PF restructuring, and its status in the grammar is not clear. Moreover, Zubizarreta argues that (26b) is unbalanced and should be changed into (27) by Heavy NP Shift:

(27) (Max put in his cár) (all the boxes of home fúrnishings)

The intonational phrasing in (27) is more natural than that in (26b). As Zubizarreta admits, however, she has not attempted to formalize this analysis. Thus, if we are to accept Zubizarreta's analysis, we need to develop a theory of intonational phrasing to deal with sentences which have more than one NS.

Furthermore, as Zubizarreta comments, "the notion of metrical heaviness is still poorly understood (p. 137)." Her generalization depends on the branchingness of the syntactic tree as shown in the RWC (23), but it is not without controversy whether or how phonology can have access to that kind of information. ${ }^{10}$ Moreover the RWC has empirical problems as well. ${ }^{11}$ Consider the following pair which involves Heavy NP Shift (p. 149): $:^{12}$

(28) a. I talked to Mary about Bill.

b.??(I talked about Bíll) (to Máry)

(28b) is unacceptable probably because to Mary is not heavier than about Bill. However, Zubizarreta's definition of the Relative Weight

10 Ghini (1993), for example, argues that prosodic weight relations, rather than syntactic branchingness, are responsible for $\phi$-formation in Italian. In section 4.2, I will propose a theory of syntax-phonology mapping which deals with the notion of "heaviness" without referring to branchingness.

11 Zubizarreta does not mention whether the RWC (23) is a universal constraint or a language specific constraint. As she remarks that Heavy NP Shift is a case of prosodically motivated movement (p. 149), I suppose that the RWC is in effect in English.

12 Zubizarreta marks (28b) with an asterisk instead of question marks. 
Constraint does not exclude (28b) because both to Mary and about Bill are branching. Branchingness predicts that these two constituents will be equally "heavy." However, this is not the case. We could strengthen the RWC by replacing "if A is 'metrically heavier' than B" with "if $\mathrm{A}$ is 'metrically heavier' than $\mathrm{B}$, or if $\mathrm{A}$ and $\mathrm{B}$ are 'metrically equally heavy." With this revised RWC, we could exclude (28b). However, with that definition, we would wrongly exclude the following Italian example (p. 23):

(29) Ha mangiato una mela solo Gianni. has eaten an apple only Gianni

Although ha mangiato una mela and solo Gianni are branching and are equally heavy, this sentence derived by p-movement is acceptable. Thus the RWC (23) is not tenable with this revision.

Another deficiency of the RWC (23) is that it only refers to the topmost nodes and does not take branchingness below them into account. Consider the following for example:

(30) a. I talked about Bill to my sister-in-law.

b. ${ }^{*}$ I talked about my brother-in-law to Mary.

(30a) is better and (30b) is worse than (28b). In these three examples all the PPs branch into P and NP, and the RWC (23) cannot predict the difference in acceptability. It is apparent that the difference comes from the relative weight of the PPs. The NPs in the PPs, my sister-inlaw and my brother-in-law, are also branching. The RWC (23) does not refer to this level of branching, however.

3.3. Unergative/Unaccusative Verbs and Stage-Level/Individual-Level Predicates

Let us turn to Zubizarreta's analysis of sentences with intransitive verbs. First, as we have seen in section 2, Zubizarreta argues that there are two possible positions of NS in sentences with unergative verbs:

(31) a. A bóy has danced. (=(13a))

b. A boy has dánced. $\quad(=(14))$

To account for this, Zubizarreta proposes the following auxiliary to convention (17) (p. 59):

(32) Auxiliary to convention [(17)] for application of the NSR (optional)

If some projections of the verbal components $V_{i}$ and $V_{j}$ of the lexical verb are metrically nondistinct, then $V_{i}$ and $V_{j}$ 
are analyzed as metrically nondistinct for the purpose of applying the interpretive convention in [(17)].

Consider the case (32) applies to the sentence in (31). Because $V_{1}$ $\left(=\left[\mathrm{v}_{1} v_{1}\left[\mathrm{v}_{2}\right.\right.\right.$ has danced $\left.\left.]\right]\right)$ and $\mathrm{V}_{2}\left(=\left[\mathrm{v}_{2}\right.\right.$ has danced $\left.]\right)$ are metrically nondistinct, their heads $\left[\mathrm{v}_{1} v_{1}\right]$ and $\left[\mathrm{v}_{2}\right.$ danced] are interpreted as metrically nondistinct. By transitivity, $\mathrm{V}_{1}\left(=\left[\mathrm{v}_{1} v_{1}\left[\mathrm{v}_{2}\right.\right.\right.$ has danced $\left.]\right)$ is metrically nondistinct from $\left[\mathrm{v}_{1} v_{1}\right]$ as well. Therefore, the sisters $\mathrm{D}_{1}(=a$ boy $)$ and $\mathrm{V}_{1}\left(=\left[\mathrm{v}_{1} v_{1}\right.\right.$ [ $\mathrm{V}_{2}$ has danced $\left.\left.]\right]\right)$ are derivatively interpreted as selectionary ordered. The S-NSR applies and assigns NS to the subject as in (31a). If (32) does not apply, the S-NSR cannot apply because $\mathrm{D}_{1}$ and $\mathrm{V}_{1}$ are not selectionally ordered. The C-NSR instead assigns NS to the verb as in (31b). Zubizarreta argues that (32) is independently supported by the structures involving defocalized constituents in German (p. 60). However, this auxiliary is still ad hoc.

Second, as we noted in section 2.2, Zubizarreta concludes that the SNSR and the C-NSR are unordered in English. This means that either rule can apply to any sentence. She also argues that in sentences with unaccusative verbs, NS can fall only on the subject, as shown in (33):13

(33) a. The sún came out.

b. ${ }^{*}$ ?The sun came out.

However, we have no way to prevent the C-NSR from applying to this sentence and assigning NS to the predicate as in (33b).

Zubizarreta's analysis has more empirical problems. First, her observation about unaccusative/unergative verbs does not agree with other linguists' judgments. As is shown in (31) and (33) above, Zubizarreta observes that in sentences with unaccusative verbs NS falls obligatorily on the subject, and that in sentences with unergative verbs NS can fall either on the verb or on the subject (I repeat (33) and (31) as (34) and (35) for ease of reference):

(34) a. The sún came out. (unaccusative)

b. ${ }^{*}$ ?The sun came out.

a. A bóy has danced. (unergative)

b. A boy has dánced.

Selkirk's $(1984,1995)$ observation is contrary to Zubizarreta's. Selkirk

13 Zubizarreta notes that "only one of the five speakers consulted accepted both options with unaccusative verbs (NS on the subject or on the verb)" (p. 176). 
argues that unaccusative verbs do not have to be prominent while unergative verbs have to be prominent (Selkirk (1995: 559)): ${ }^{14}$

(36) a. The SUN's shining.

(unaccusative)

b. The SUN is SHINing.

(37) a. ${ }^{*} \mathrm{JOHN}$ was dancing.

(unergative)

b. JOHN was DANCing.

Note that Selkirk uses the term pitch accent instead of NS, and identifies two prominent words in (36b) and (37b). The second pitch accented word is perceived as more prominent than the first because the nucleus of intonation falls on the last pitch accented word (cf. Schmerling (1976)). Thus I assume here that Zubizarreta's NS pattern in (34b) and (35b) basically corresponds to Selkirk's (36b) and (37b) respectively.

Then it is necessary for us to explain these contradictory observations. Zubizarreta mentions the examples with the verb die (p. 69), and attributes the ambiguity in the place of NS to the discourse context, citing Schmerling (1976). She does not show other examples from Selkirk $(1984,1995)$ such as $(36)$, however. We should seek for the analysis which can explain all the cases. I will propose such an alternative analysis in section 4 .

Zubizarreta also shows the contrast between existential subjects and generic subjects (p. 66) $:^{15}$
a. weil
Féuerwehrmänner verfügbar sind because the-firemen available are
b. weil
Feuerwehrmänner because the-firemen
altruistic are

14 Example (37) is taken from Heycock (1994: 159), who cites Selkirk's observation. Allerton and Cruttenden (1979) show the unaccusative/unergative pairs as the following:
(i) a. JOHN died.
b. John proTESTed.
(ii) a. ... My COUsin's coming.
b. ... My cousin's CELebrating.

These examples are also referred to by Gussenhoven (1983). Then it may well be argued that NS is likely to fall on the subject in sentences with unaccusative verbs while it is likely to fall on unergative verbs in sentences containing them. See section 4.

15 sind is written in italics because Zubizarreta assumes that function words are metrically invisible for the NSR (p. 47). 
Whereas NS falls on the existentially interpreted subject in (38a), it falls on the predicate in (38b). In other words, stage-level predicates such as 'are available' do not have NS while individual-level predicates such as 'are altruistic' have NS (Gussenhoven (1983), Selkirk (1995)). Zubizarreta argues that the contrast derives from the assumption that (38a) is analyzed as a raising structure and (38b) as a control structure (Diesing (1992), Selkirk (1995)). The subject in (38a) is an argument of the adjective and the subject in (38b) is not. Then the S-NSR applies in (38a), but not in (38b). However, if we assume a raising structure for (38a), we need to apply the auxiliary (32) to make the S-NSR applicable. Zubizarreta assumes that the auxiliary (32) is optional. This means that we expect ambiguity in the position of NS in sentences with existential subjects, just like with unergative verbs (cf. (35)). In other words, we expect the following pattern, which Zubizarreta does not include:

(39) weil Feuerwehrmänner verfúgbar sind because the-firemen available are

However, this stress pattern is not acceptable unless Feuerwehrmänner has been previously introduced into the discourse. Zubizarreta also suggests an alternative analysis to the effect that generic subjects are bona fide sentence topics and cannot carry the NS within a phrase. This functional approach seems to be on the right track, but it is not an easy task to specify what kind of subject is a sentence topic. Moreover, there are examples where generic subjects may have NS (Bolinger (1985: 105)):

(40) a. How strange! Dólphins are mammals. Did you know that?

b. I've just learned that asbéstos is dangerous. Have we got any of the stuff about the house?

Then we have to allow sentence topics to carry NS in some cases.

Moreover, according to Selkirk's observation, there is an interesting parallelism between unaccusative/unergative verbs and stage-level/ individual-level predicates ((36) and (37) repeated here as (41) and (42)):

(41) a. The SUN's shining.

(unaccusative)

b. The SUN is SHINing.

(42) a. ${ }^{*} \mathrm{JOHN}$ was dancing.

b. JOHN was DANCing.

(unergative)

a. FIREmen are available.

(stage-level predicate) 
b. FIREmen are aVAILable.
a. *FIREmen are altruistic.
(individual-level predicate)
b. FIREmen are altruIStic.

If this observation is right, Zubizarreta fails to capture an important generalization because she cannot give any unified analysis of these contrasts. I will present an analysis that unifies these cases in section 4.

Finally, Zubizarreta notes that (45a) and (45b) as answers to (46) do not have the same communicative value:

(45) a. The báby's crying.

b. The baby's crýing.

(46) What's happening?

She claims that in (45a) the speaker intends to convey to the listener that the lexical content of the subject is informationally relevant ( $p$. 173). However, it is hard to understand what she means by 'informationally relevant.' Whether the lexical content of the subject is informationally relevant or not depends on the context, which is in fact the same for (45a) and (45b), namely (46). Thus Zubizaretta's analysis cannot predict whether NS falls on the subject or on the predicate in such cases as (45). In the next section I will argue that (45a) and (45b) reflect two kinds of judgment by the speaker.

\section{An Alternative Account}

\subsection{Thetic/Categorical Judgment}

In this section I will propose an alternative account to explain the data concerning unergative and unaccusative verbs. Let us look at more data and reconsider all the data from a different perspective. Unergative verbs do not have NS in some cases, such as the following:

(47) a. Your MOTHer telephoned.

b. Sssh! The CHILDren're listening! (Faber (1987: 349)) Some contexts can also make unergative verbs accentless as in the following examples (Gussenhoven (1992: 103)):

(48) a. (Why have they stopped the traffic?) JOHN is jogging today.

b. (Why is SHE here?) Her HUSband beats her.

Notice that unergative verbs do not need pitch accent when they are the predicates in small clauses. The following examples contain complements of perception verbs, which are typical small clauses (I under- 
line the (small) clauses in question):

(49) a. I heard a BIRD sing.

b. I heard a CLOCK tick.

(Gussenhoven (1992: 95))

(Selkirk (1995: 559))

Similarly, small clauses appear after it's (just) as in the following sentences:

(50) a. It's just a BAby crying.

b. ?It's just the SECretary typing.

(Faber (1987: 356))

These examples are problematic for Selkirk's (1995) analysis. She claims that unergative verbs are prominent.

Note in passing that Selkirk's distinction between stage-level predicates and individual-level predicates is problematic. Individual-level predicates do not need pitch accents in some cases. Gussenhoven's (1983: 396) example is interesting in that it is uttered in an out-of-theblue context:

(51) (Adam, upon first seeing Eve:) Your EYES are blue! I LOVE blue!

Blue is an individual-level predicate, but it is not pitch accented in (51). Also in the answer to a question asking for a reason, individual-level predicates do not need pitch accent:

(52) (Why didn't you come here by car?) The ROAD is bad!

(Jäger (1997: 234))

This is the same if the reason clause is embedded in a main clause:

(53) a. I love CaliFORnia because its CLImate is so nice.

(attested)

b. I can't READ much of THINGS like that anyway cos my EYES are too bad.

(London-Lund Corpus)

The predicates in the underlined clauses of (52) and (53) are individuallevel predicates, but they do not have pitch accent. Selkirk's explanation based on the stage-level/individual distinction cannot deal with these examples.

To explain all the data shown above, let us introduce here the notion thetic/categorical judgment. The terms thetic/categorical judgment were invented by the 19th century philosopher, Franz Blentano and his successor Anton Marty. In contemporary linguistics this notion was first revived by Kuroda (1972). Kuroda (1992: 21) defines the distinction in the following way:

(54) a. Thetic judgments: ... simply express recognition of the existence of an entity or a situation. ... a simple form of a judgment, a unitary cognitive act. ... a simple 
judgment.

b. Categorical judgments: ... conform to the Subject-Predicate form ... two distinct cognitive acts, one the recognition of the Subject, ..., and another the act of acknowledging or disavowing a Predicate of a Subject. ... a double judgment.

The original examples of Blentano and Marty, cited by Kuroda (1972: 154), are the following:

(55) a. Es regnet.

it rains

b. Es gibt gelbe Blumen.

it gives yellow flowers

'There are yellow flowers.'

(56) a. Der Körper ist auf der Erde.

the body is on the earth

b. Ich urteile.

I judge

According to Blentano and Marty, the sentences in (55) are thetic because their grammatical subjects are the pleonastic es, and not lexical subjects. The sentences in (56) are claimed to be categorical because they have subject-predicate form.

Kuroda (1972) argues that the thetic/categorical distinction is expressed by the two particles, $-g a$ and $-w a$ in Japanese. The following examples are taken from Kuroda (1992: 21):

(57) a. Neko-ga asokode nemutte iru. (thetic) cat-Prt there sleeping be 'A cat is sleeping there.'

b. Neko-wa asokode nemutte iru. (categorical) cat-Prt there sleeping be 'The cat is sleeping there.'

Kuroda argues that $-g a$ marks the subject of thetic clauses and that $-w a$ marks the subject of categorical clauses.

Now let us turn to the prosody of thetic/categorical clauses. Sasse (1987:520) argues that accentuation of the subject and the predicate reflects the thetic/categorical distinction in English:

(58) a. The BUTter melted. (thetic)

b. The BUTter MELTed. (categorical)

The sentence (58a) has pitch accent only on its subject. According to Sasse, this shows that the clause consists of a conceptual unit and is 
thetic. (58b) is categorical in that it has pitch accent both on the subject and the verb. We may argue that a categorical clause consists of two conceptual units. ${ }^{16}$

Note that in $(58 \mathrm{~b})$ the hearer perceives the subject to have secondary stress. Bing (1979:140) argues that this is because the subject has a non-final contour with a continuation rise. The predicate is heard as more prominent than the subject in (58b) because it is uttered with sentence-final falling intonation. ${ }^{17}$ I propose the following hypotheses:

(59) a. A thetic clause contains one conceptual unit and a categorical clause two conceptual units.

b. In a conceptual unit, the most informative word has prominence.

c. In a sentence, the last prominent word which is not defocalized is heard as most prominent.

In (59b), I simply assume here that nouns are more informative than predicates except when (i) they are defocalized and/or anaphoric, or (ii) predicates have emphatic stress (see Schmerling (1976: 82) and Bing (1979: 126) for discussion).

According to (59), in (58a), which is thetic and consists of one conceptual unit, butter is the most informative word and has prominence. (58b), which is a categorical clause, contains two conceptual units, and

16 See Chafe (1974: 115) for the notion of conceptual units. See also Lambrecht (1994) and Lambrecht and Michaelis (1998) for the prosodic expression of the thetic/categorical judgment. However, they do not discuss the relation between thetic/categorical judgment and unaccusative/unergative verbs or stage/individual predicates.

The thetic/categorical judgment basically corresponds to the use of $-g a /-w a$ in Japanese.

(i) a. Bataa-ga toketa. butter-Prt melted

'The BUTter melted.'

b. Bataa-wa toketa.

butter-Prt melted

'The BUTter MELTed.'

Thus we can use Japanese translations as a test of thetic/categorical judgment. Although I will not show Japanese translations of the example sentences until (71), $-g a /-w a$ distinction is clear in all of them. See also footnote 20.

17 Bing (1979: 140-142, 171) shows that both the intensity and height of the $F_{0}$ contour of the subjects are as great as those of the predicate. 
butter and melted are prominent in each unit. Melted is heard as more prominent than butter. $^{18}$

Now let us try to solve the problems we have seen in section 3 . First, unaccusative verbs and stage-level predicates do not need pitch accent or prominence:

(60) a. The SUN's shining.

b. FIREmen are available.

This is because clauses with these verbs and predicates are thetic in the unmarked case. Unaccusative verbs, such as shine, introduce a new entity into the discourse and make the clause thetic. Stage-level predicates, such as be available, express the existence of a situation and make the clause thetic. However, it is also possible for the speaker to utter these sentences as a categorical judgment because they have lexical subjects:

(61) a. The SUN is SHINing.

b. FIREmen are aVAILable.

In (61), the speaker first introduces the subject as the topic of the sentence and then comments on it with the predicate. This is the marked option (see also footnote 14).

On the other hand, unergative verbs and individual-level predicates typically need pitch accent or prominence, because they describe their subject and make the clauses categorical. For example, be dancing or be altruistic below are descriptions of the subject, and are the second judgment.

(62) a. *JOHN was dancing.

b. *FIREmen are altruistic.

a. JOHN was DANCing.

b. FIREmen are altrIStic.

We can claim that clauses with unergative verbs and individual-level predicates are basically categorical.

Then we can give a natural answer to the problematic examples we

18 An anonymous reviewer has pointed out that the predicates in (67) and (70a, b) are predictable or inferable from the preceding discourse, and that 'Because of the ROAD,' 'because of its CLImate,' and 'because of my EYES' could replace them. However, the predicates are not perfectly predictable or inferable. In (67), for example, the predicate could be icy or wet instead of bad. The point is that nouns are more informative than predicates, as mentioned above. 
have seen so far. Unergative verbs and individual-level predicates lack pitch accent or prominence only if the speaker utters the whole clause as a single judgment, not as a double judgment, as shown in (64) and (65).

(64) a. Your MOTHer telephoned.

b. Sssh! The CHILDren're listening! (Faber (1987: 349))

(65) (Adam, upon first seeing Eve:) Your EYES are blue! (I LOVE blue!)

In other words, these sentences express recognition of the existence of a situation (cf. (54a)). This is clearer in the examples in (66) and (67):

(66) a. (Why have they stopped the traffic?) JOHN is jogging today.

b. (Why is SHE here?) Her HUSband beats her.

(67) (Why didn't you come here by car?) The ROAD is bad!

(Jäger (1997: 234))

These clauses are answers to questions asking for a reason. The speaker could answer the questions in the following way:

(68) a. They have DONE it because JOHN is jogging today.

b. She is HERE because her HUSband beats her.

(69) I DIDn't because the ROAD is bad!

In $(68 a, b)$ and $(69)$, the main clause is the topic and the subordinate clause is a comment on it. Then in $(66 a, b)$ and $(67)$, the answer sentence itself is a single judgment and is thetic. Thus it has pitch accent or prominence only on the subject.

Then the examples in (70) are straightforward:

(70) a. I love CaliFORnia because its CLImate is so nice. (attested)

b. I can't READ much of THINGS like that anyway cos my EYES are too bad. (London-Lund Corpus)

These sentences have two clauses and express double judgment as a whole: the main clause serves as the topic of the sentence and the subordinate clause as the comment on it. The underlined clause itself is thetic in that it expresses a simple judgment. ${ }^{19}$

19 (19B) also has two conceptual units, and hat and rat are prominent in each unit. The last prominent word which is not defocalized is hat, not rat. The latter is defocalized and is less prominent than the former. 
Our claim that the clauses in question are thetic is supported by the Japanese data in (71)-(73), which are translations of (51)-(53). The topic marker -wa cannot appear in the clauses, which shows that they cannot be categorical:

(71) Adam (...): Me-ga/*wa aoi! Boku-wa ao-ga suki! eyes-Prt/Prt blue I-Prt blue-Prt love

(72) A: Naze kuruma-de kokoni konakatta-no? why car-Instr here came not-Q

B : Michi-ga/*wa warui(-kara(-da))! road-Prt/Prt bad-because-it's

(73) a. California-ga suki, kikoo-ga/*wa totemo ii-kara California-Prt love climate-Prt/Prt so nice-because

b. Son-na-no-wa yom-e-nai, me-ga/*wa That-like-things-Prt read-can-Neg eyes-Prt/Prt warui-kara. bad-because

As we saw in the last section, another case which seems to be exceptional is small clauses. We can argue that small clauses are thetic because they typically occur as the complement of perception verbs. The speaker perceives and recognizes the existence of a situation. Thus examples (49) and (50) are straightforward. They contain small clauses which have pitch accent or prominence only on the subject:

(74) a. I heard a BIRD sing.

b. I heard a CLOCK tick.

(75) a. It's just a BAby crying.

b. ?It's just the SECretary typing.

(Gussenhoven (1992: 95))

(Selkirk (1995: 559))

(Faber (1987: 356))

The Japanese translation gives us evidence that these are thetic because - wa cannot appear in the small clauses:

(76)
a. Tori-ga/*wa utau-no-o kiita.
'I heard a bird sing.'
b. Akanboo-ga/*wa naiteru-n-da. baby-Prt/Prt crying-Nml-it's 'It's a baby crying.'

Ikawa (1998) also claims that complements of perception verbs are thetic. ${ }^{20}$ 
In this section we have argued that we can describe the data shown in section 3 in terms of the thetic/categorical judgment distinction. We have also seen that our explanation can deal with the examples that were problematic for Zubizarreta (1997) and Selkirk (1995). Thus this is a more general way to explain the prosody in sentences with unaccusative/unergative verbs and stage/individual-level predicates, with no obvious empirical problems. ${ }^{21}$

\subsection{Intonational Phrasing}

In this section I will explore how we can formalize intonational phrasing in the minimalist framework. ${ }^{22}$ The syntax-phonology mapping rule I propose here is (77):

(77) Interpret boundaries of syntactic constituents [...] as prosodic boundaries /.../.

This rule interprets boundaries of syntactic constituents as metrical boundaries which have no direction, like bars in music. I assume here that the input to rule (77) is the bare phrase structure of Chomsky (1995), and not the X-bar theoretic phrase structure. I also assume that the rule does not see phonologically invisible elements such as Infl, trace, and PRO. For example, rule (77) maps the right branching structure (78a) into the PF representation (78b):

(78) a. $[[\mathrm{X}][[\mathrm{Y}][\mathrm{Z}]]]$

b. // X /// Y // Z ///

In (78b), we have two boundaries before $X$, three between $X$ and $Y$, two between $\mathrm{Y}$ and $\mathrm{Z}$, and three after $\mathrm{Z}$.

In this bare mapping theory, phrasing means grouping words by deleting prosodic boundaries, and its rule is (79), where $n$ is a variable:

following:

(i Kingyo-ga neko-ni osowareteiru goldfish-Prt cat-by is being attacked 'A goldfish is being attacked by a cat.'

I refer to this type of clause as semi-thetic in Tokizaki (1999a).

21 A reviewer points out that I should give an independent way of identifying the thetic/categorical distinction that does not rely on accentuation. I have not found any way of doing it in English. However, as I have shown in (71)-(73) and (76), the particles $-g a / w a$ in the Japanese translation give us indirect evidence that the corresponding English clauses are thetic or categorical. See also footnote 16.

22 A part of this section has appeared in Tokizaki (1999b). 
(79) Delete $n$ boundaries between words. ( $n$ : a natural number) For example, supposing that $n$ is 1,2 , or 3 , and applying (79) to (78b), we get $(80 \mathrm{a}, \mathrm{b}, \mathrm{c})$, respectively:

(80)
a. / $\mathrm{X} / / \mathrm{Y} / \mathrm{Z} / /$
$(n=1) \quad \rightarrow$
$(\mathrm{X})(\mathrm{Y})(\mathrm{Z})$
b. $\mathrm{X} / \mathrm{Y} \mathrm{Z} /$
$(n=2) \quad \rightarrow$
$(\mathrm{X})(\mathrm{Y} Z)$
c. $\mathrm{X} Y \mathrm{Z}$
$(n=3) \rightarrow$
(X Y Z)

In (80a), one boundary is deleted in every sequence of boundaries, resulting in two boundaries between $\mathrm{X}$ and $\mathrm{Y}$, and one boundary between $\mathrm{Y}$ and $\mathrm{Z}$, so we get $(\mathrm{X})(\mathrm{Y})(\mathrm{Z})$ phrasing. In (80b), two boundaries are deleted in every sequence of boundaries, leaving one boundary between $\mathrm{X}$ and $\mathrm{Y}$, but no boundary between $\mathrm{Y}$ and $\mathrm{Z}$, so we get $(\mathrm{X})(\mathrm{Y} \mathrm{Z})$. There is no boundary left in (80c) after three boundaries are deleted in every sequence of boundaries. The whole string is contained in a phrase as (X Y Z). I assume here that the variable $n$ relates to speech rates or phrasing levels. The basic idea is that if the speaker utters the sentence faster, more boundaries are deleted, and we get bigger phrases.

Now let us look at the examples of intonational phrasing discussed by Zubizarreta.

(81) a. (Max pút) (all the boxes of home fúrnishings) (in his cár).

b. (Max put in his cár) (all the boxes of home fúrnishings). Zubizarreta mentions that because (81a) is "unbalanced, such intonational phrasings sound awkward" (p. 149). If we use our mapping theory, we can state the awkwardness in specific terms. The bare phrase structures of the sentences $(81 \mathrm{a}, \mathrm{b})$ are the following:

(82) a. [Max [put [all [the [boxes [of [home furnishings]]]]] [in [his car]]]

b. [Max [put [in [his car]] [all [the [boxes [of [home furnishings ]]1]]]]

(83) a. / Max / put / all / the / boxes / of / home furnishings /III/ in / his car //I

b. / Max / put / in / his car /// all / the / boxes / of / home furnishings //II/I/

Suppose that languages prefer fewer boundaries between words in a sentence. Then (83a) is not preferable because there are six boundaries between furnishings and in. Let us assume the following condition for Heavy NP Shift:

(84) Heavy NP Shift satisfies Last Resort when there are a large 
number of boundaries between the NP and the constituent following it.

Heavy NP Shift can apply to (82a) to give (82b), which is then mapped to $(83 b)$. (83b) is preferable because it has only three boundaries between car and all. Thus we can make explicit the idea of awkward or unbalanced phrasing with this mapping theory. ${ }^{23}$

Note that another advantage of using this theory of phrasing is that we can formalize the notion of "heaviness" in terms of boundaries. With the theory proposed here, we can predict the unacceptability of (28b) above. If we assume Larson's (1988) light predicate raising for the Heavy NP Shift, the structures of $(28 \mathrm{a}, \mathrm{b})$ are the following: ${ }^{24}$

(85) a. [I [talked [[to Mary] [about Bill]]]]

b. [I [[talked [about Bill] $]_{\mathrm{i}}$ [to Mary] $\left.\left.t_{i}\right]\right]$

If we apply the mapping rule (77) to $(85 \mathrm{a}, \mathrm{b})$, we get the following:

(86) a. / I / talked // to Mary // about Bill ////

b. / I // talked / about Bill /// to Mary //

The maximum number of boundaries between words in (a) is two while it is three in (b). Thus the movement of talked about Bill does not reduce the maximum number of boundaries in the sentence, and in fact it increases the number. Then the movement does not satisfy condition (84), and (85b) cannot be derived.

It might be argued that this mapping theory cannot handle the socalled syntax-prosody mismatches, like the following example from Chomsky and Halle (1968: 372):

(87) a. [[This] [[is] [[the] [[cat] [[that] [[caught] [[the] [[rat] [[that] [[stole] [[the] [cheese]]]]]]]]]]]]

b. // This /// is /// the /// cat /// that /// caught /// the /// rat //I that /// stole /// the // cheese $/ / I / I / I / I / I$

c. (This is the cat) (that caught the rat) (that ate the cheese)

Our rule (77) maps (87a) to (87b). Given that there are no more

23 Moreover, as a reviewer points out, no amount of deletion will put Max and put together as a single intonational phrase in (83a). See also Tokizaki (1988) for unbalanced phrasing.

24 I assume here that the outermost brackets in [[to Mary] $\left.t_{i}\right]$ are invisible because $t_{i}$ is invisible. Thus [[to Mary] $\left.t_{i}\right]$ is not distinct from [to Mary] for phonological rules. 
boundaries after cat and rat than in any other place in (87b), how do we get the actual phrasing (87c)?

Chomsky (1998:20) argues that a phase of derivation is $\mathrm{CP}$ or $v \mathrm{P}$, and that derivation proceeds phase by phase. (88), for example, has the four phases bracketed:

(88) [John [ $t$ thinks [ Tom will [ $t$ win the prize $]]]]$ Chomsky (1998: 48) further proposes that Spell-Out is contingent on feature-checking operations and that Spell-Out applies cyclically, possibly at the phase level, in the course of the (narrow syntactic) derivation. Let us assume that this approach is correct and consider the derivation of (87a). Then (87a) has the six phases bracketed below:

(89) [This [is the cat [that [caught the rat [that [stole the cheese]]]]]]

The following structures are sent to PF in turn in the course of the derivation:

(90) a. [[stole] [[the] [cheese $]]]$

b. [that]

c. [[caught] [[the] [rat $]]]$

d. [that]

e. [[is] [[the] [cat]]]

f. [this]

If we assume that the mapping rule (77) applies every time a structure is sent to PF, the outputs are (91):

(91) a. // stole /// the // cheese ///

b. / that /

c. // caught /// the // rat ///

d. / that /

e. // is /// the // cat ///

f. / this /

After the whole sentence (87a) is sent to PF, its PF representation is (92):

(92) / this / // is /// the // cat /// / that / / caught // the // rat /// / that / // stole /// the // cheese ///

In (92), there are four boundaries before the two occurrences of that. Thus we predict the phrasing (87c) straightforwardly. If we apply the phrasing rule (79) with $n=3$, we get the right result (93):

(93) this is the cat / that caught the rat / that stole the cheese Thus we can explain this case without the readjustment rule assumed in Chomsky and Halle (1968: 372), which converts sentences with (multi- 
ple) embedded clauses into sentences dominating sister-adjoined clauses. ${ }^{25}$

\subsection{Prominence and Phrasing}

In this section, I would like to show in brief how our analyses of prominence and phrasing can be put together to predict the prosody of various sentences. Let us consider the example (70a) above (repeated here as (94)).

(94) [I [love CaliFORnia]] [because [[its CLImate] [is [so nice]]]]] The rule (77) applies to (94) to give (95):

(95) / I / love CaliFORnia /// because // its CLImate // is / so nice $/ / / / /$

If we apply (79) with $n=2$, we get the following phrasing:

(96) a. I love CaliFORnia / because its CLImate is so nice //I

b. (I love CaliFORnia) (because its CLImate is so nice)

The whole sentence (96b) is categorical in the sense that the first intonational phrase is the topic and the second is a comment on it. As we argued above, the second intonational phrase in (96b) is a thetic clause and consists of a unit. The hypothesis $(59 \mathrm{~b})$ predicts that climate gets prominence because it is the most informative word in the unit. Because the clause is thetic, the predicate is so nice does not have prominence, in spite of the fact that it is an individual-level predicate. ${ }^{26}$

25 Our mapping theory also explains why "not all root transformations result in an obligatory contour on the moved constituent" (Bing (1979: 228)):

(i) a. (Up the street) (trotted the dog)

b. (Here comes John)

The phrase structures of these sentences are the following:

(ii ) a. $[[[\mathrm{Up}][[$ the $][$ street $]]][[$ trotted $][[$ the $][$ dog $]]]]$

b. [[Here] [[comes] [John]]]

If we apply the mapping rule (77) and the phrasing rule (79) with $n=3$, we get the right result:

(iii) a. Up the street // trotted the $\operatorname{dog} /$

b. Here comes John

I am grateful to an anonymous reviewer for drawing my attention to this point.

26 In the first intonational phrase of (96b), California gets prominence because it is more informative than $I$ and love. Note that love instead of California may have an accent when it is emphasized and more informative than the nouns (see the discussion immediately below (59)):

(i ) (I LOVE California) (because its CLImate is so nice) 


\section{Conclusion}

In this article I reviewed Zubizarreta (1998) and pointed out some problems concerning the modularized NSR, PF Restructuring, the Relative Weight Constraint, and unergative/unaccusative verbs. I also proposed an alternative analysis for sentences with intransitive verbs in terms of thetic/categorical judgment, and proposed a theory of phrasing in the minimalist framework.

Zubizarreta's work shows a new approach to the syntax-phonology interface in the minimalist framework. Some recent ideas in syntax such as lexico-syntactic structure and asymmetric c-command are claimed to be involved in determining NS. Zubizarreta also claims that some movements in Romance are motivated by phonology. In this sense, her work is syntax-oriented compared with more phonologyoriented work such as Selkirk (1984). I believe this field will develop further if researchers consider other components of grammar than their own. I hope that more research will be done on the syntax-phonology interface by syntacticians as well as phonologists in the future.

\section{REFERENCES}

Allerton, David and Alan Cruttenden (1979) "Three Reasons for Accenting a Definite Subject," Journal of Linguistics 15, 49-53.

Bing, Janet Mueller (1979) Aspects of English Prosody, Doctoral dissertation, University of Massachusetts, Amherst. [Distributed by GLSA, University of Massachusetts, Amherst. Published by Garland, New York, 1985.]

Bolinger, Dwight (1985) "Two Views of Accent," Journal of Linguistics 21, 79-123.

Chafe, Wallace (1974) "Language and Consciousness," Language 50, 111-133.

Chomsky, Noam (1972) Studies on Semantics in Generative Grammar, Mouton, The Hague.

Chomsky, Noam (1976) "Conditions on Rules of Grammar," Linguistic Analysis $2,303-351$.

Chomsky, Noam (1995) The Minimalist Program, MIT Press, Cambridge, MA.

Chomsky, Noam (1998) Minimalist Inquiries: The Framework, MIT Occasional Papers in Linguistics 15.

Chomsky, Noam and Morris Halle (1968) The Sound Pattern of English, Harper and Row, New York.

Cinque, Guglielmo (1993) "A Null Theory of Phrase and Compound Stress," Linguistic Inquiry 24, 239-298. 
Diesing, Molly (1992) Indefinites, MIT Press, Cambridge, MA.

Faber, David (1987) "The Accentuation of Intransitive Sentences in English," Journal of Linguistics 23, 341-358.

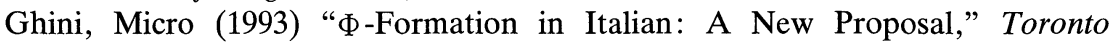
Working Papers in Linguistics 12.2, 41-78.

Gussenhoven, Carlos (1983) "Focus, Mode and the Nucleus," Journal of Linguistics $19,377-417$.

Gussenhoven, Carlos (1992) "Sentence Accents and Argument Structure," Thematic Structure: Its Role in Grammar, ed. by Iggy M. Roca, 79-106, Foris, Dordrecht.

Hale, Kenneth and Samuel Jay Keyser (1993) "On Argument Structure and the Lexical Expression of Syntactic Relations," The View from Building 20: Essays in Linguistics in Honor of Sylvain Bromberger, ed. by Kenneth Hale and Samuel Jay Keyser, 53-109, MIT Press, Cambridge, MA.

Heycock, Caroline (1994) "Focus Projection in Japanese," NELS 24, 157-171.

Ikawa, Hisako (1998) “Thetic Markers and Japanese/Korean Perception Verb Complements," Japanese/Korean Linguistics 7, 329-345, CSLI Publications, Stanford.

Jackendoff, Ray (1972) Semantic Interpretation in Generative Grammar, MIT Press, Cambridge, MA.

Jäger, Gerhard (1997) "The Stage/Individual Contrast Revisited," WCCFL 15, 225-239.

Kayne, Richard S. (1994) The Antisymmetry in Syntax, MIT Press, Cambridge, MA.

Kuroda, S.-Y. (1972) "The Categorical and the Thetic Judgment," Foundations of Language 9, 153-185.

Kuroda, S.-Y. (1992) Japanese Syntax and Semantics, Kluwer, Dordrecht.

Lambrecht, Knud (1994) Information Structure and Sentence Form: Topic, Focus, and the Mental Representations of Discourse Referents, Cambridge University Press, Cambridge.

Lambrecht, Knud and Laura A. Michaelis (1998) "Sentence Accent in Information Questions: Default and Projection," Linguistics and Philosophy 21, 477-544.

Larson, Richard K. (1988) "On the Double Object Construction," Linguistic Inquiry 19, 335-391.

Sasse, Hans-Jürgen (1987) "The Thetic/Categorical Distinction Revisited," Linguistics 25, 511-580.

Schmerling, Susan F. (1976) Aspects of English Sentence Stress, University of Texas Press, Austin.

Selkirk, Elisabeth O. (1984) Phonology and Syntax: The Relation between Sound and Structure, MIT Press, Cambridge, MA.

Selkirk, Elisabeth O. (1995) "Sentence Prosody: Intonation, Stress, and Phrasing," The Handbook of Phonological Theory, ed. by John A. Goldsmith, 550-569, Basil Blackwell, Cambridge, MA. 
Tokizaki, Hisao (1988) "Variable Intonational Phrasing in English," Proceedings of the Tokyo Linguistics Forum 1st Summer Conference, 149-162.

Tokizaki, Hisao (1999a) "Prosody and Information in Japanese and English," Bunka to Gengo 50,133-160, Sapporo University.

Tokizaki, Hisao (1999b) "Prosodic Phrasing and Bare Phrase Structure," NELS 29, 381-395.

Department of English

Sapporo University

Nishioka 3-7

Sapporo 062-8520

e-mail: toki@sapporo-u.ac.jp 